\title{
Inflammatory Breast Cancer: A Case Report
}

\author{
Zacharoula Sidiropoulou Lurdes Ramalho Rosa Madureira \\ Senology Department, Hospital N. S. Rosário, Barreiro, Portugal
}

\section{Key Words}

Breast cancer: locally advanced, metastatic .

Bone metastasis · Differential diagnosis · Inflammation

\section{Summary}

Background: Inflammatory breast cancer is a rare, yet controversial, syndrome of invasive breast cancer. Case Report: A female, Caucasian, 57-year-old patient presented at the emergency department with complaints suggestive of inflammatory breast cancer. Conclusions: Inflammatory breast cancer, besides the advances on its molecular profile, still remains a clinical entity difficult to diagnose, especially in the primary health care setting.

\section{Introduction}

Inflammatory breast cancer is a rare syndrome of invasive breast cancer that is characterized by erythema and oedema of a third or more of the skin of the breast, with a palpable border to the erythema, and no palpable breast mass. The differential diagnosis includes cellulites of the breast or mastitis. Pathologically, tumour tissue is typically present in the dermal lymphatics of the involved skin, but dermal lymphatic involvement is neither required nor sufficient by itself for the diagnosis of inflammatory breast cancer [1].

\section{Case Report}

A female, Caucasian, 57-year-old obese patient presented at the emergency department of our hospital and reported that 1 year ago she had

\author{
Schlüsselwörter \\ Mammakarzinom: lokal fortgeschrittenes, metastasiertes . \\ Knochenmetastasen · Differentialdiagnose · Entzündung
}

\section{Zusammenfassung}

Hintergrund: Das inflammatorische Mammakarzinom ist ein seltenes und gleichzeitig kontroverses Syndrom der invasiven Brustkrebserkrankungen. Fallbericht: Eine 57jährige Patientin weißer Hautfarbe wurde in der Notaufnahme mit Beschwerden vorstellig, die auf ein inflammatorisches Mammakarzinom hindeuteten. Schlussfolgerungen: Abgesehen von Fortschritten bezüglich seines molekularen Profils ist das inflammatorische Mammakarzinom nach wie vor eine schwierig zu diagnostizierende klinische Entität, besonders in der primären medizinischen Versorgung. felt a small lump in her breast; over the last 2 months the breast had become much bigger, heavy, itchy, and hot, and had taken on a celluliteslike appearance. She also complained of pain in her right leg, which she had been treating over the last months with acupuncture and homeopathic drugs, but with no results. Her anamnesis included G3P3, menarche at 11 years, and menopause at 46 . All 3 children were breastfed for 12 months, and were all healthy. The patient's mother and 2 maternal aunts died of pre-menopausal breast cancer. No other important anamnestic data or former medical visits were reported.

Clinical examination revealed obesity, urinary and faecal incontinence, and paralysis of both lower limbs. The left breast showed widespread erythema and intense oedema with peau d'orange, and was augmented in size with an enormous and ill-defined mass with areolar erosion (fig. 1.) and axillary pathological node involvement. A total body computed tomography scan revealed C1, L2, and L3 lytic lesions with medullar compression, and multiple disseminated lytic foci in cranial, chest, arm, and leg bones. No other secondary deposits were observed (figs. 2 and 3). A tru-cut biopsy of the breast, a fine needle aspiration biopsy of the axillary nodes, and a biopsy of the skin of the breast were performed immediately and all revealed ductal invasive carcinoma, GII,

\begin{tabular}{ll}
\hline KARGER & @ 2009 S. Karger GmbH, Freiburg \\
Fax +497614520714 & Accessible online at: \\
Information@Karger.de & www.karger.com/brc \\
www.karger.com &
\end{tabular}

\section{KARGER}




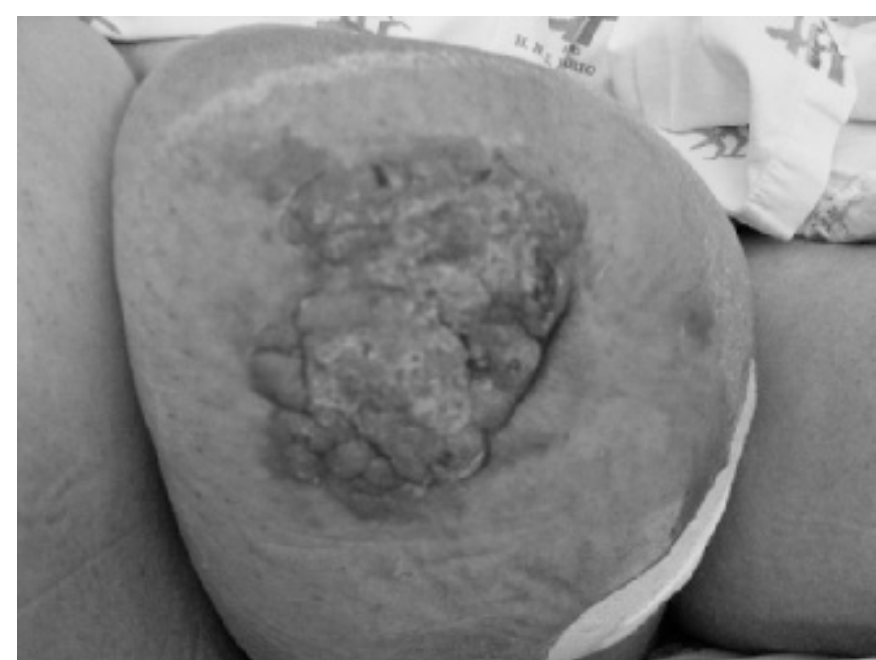

Fig. 1. Left breast with oedema, erythema, peau d'orange and nipple areolar complex involvement.

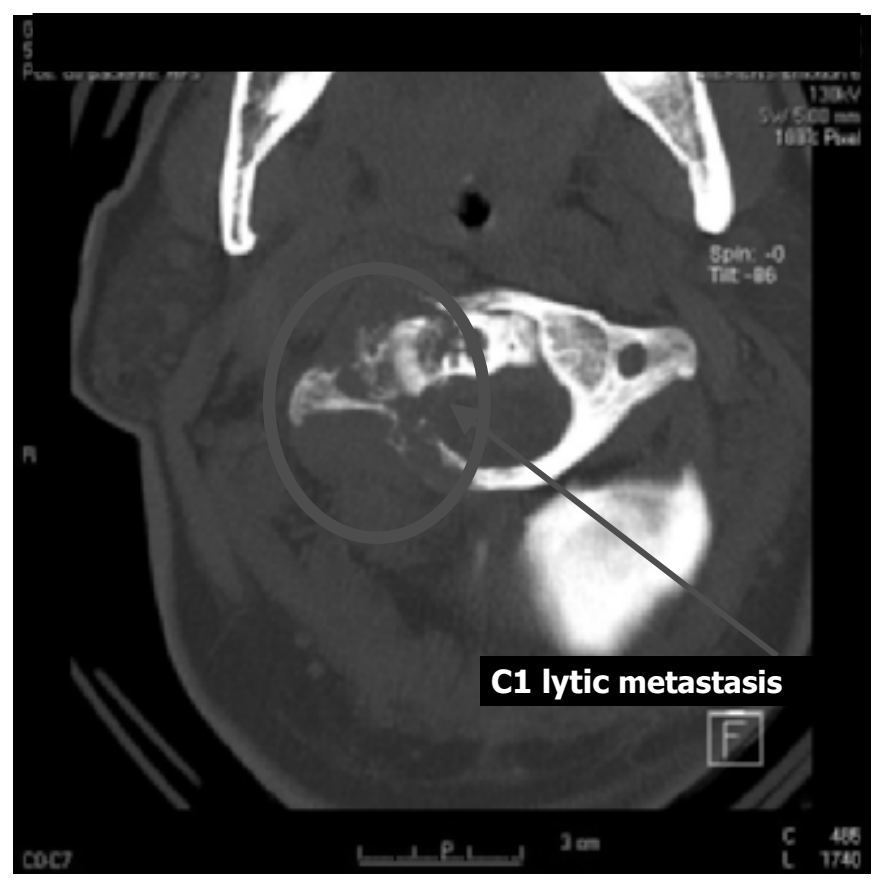

Fig. 2. Computed tomography scan of cervix.

oestrogen and progesterone receptor-positive, and HER2/neu-positive, with dermal invasion and absence of lymphatic emboli (fig. 4). Tumour markers were as follows: CEA, $47.5 \mathrm{ng} / \mathrm{ml}$; CA 15.3, $25.3 \mathrm{U} / \mathrm{ml}$; CA 19.9, $58.4 \mathrm{U} / \mathrm{ml}$; CA 125 normal. All other parameters including renal and liver function were normal. The patient was transferred to the oncology department, and after being presented to the breast committee, was started on analgesics, a biphosphonate protocol, and spinal column palliative radiotherapy. At present, the patient is receiving psychological care and physiotherapy. The treatment plan to be followed includes aromatase inhibitor (letrozole) and trastuzumab/chemotherapy protocols. At a later stage, a 'cleaning mastectomy' versus breast radiotherapy will be considered.

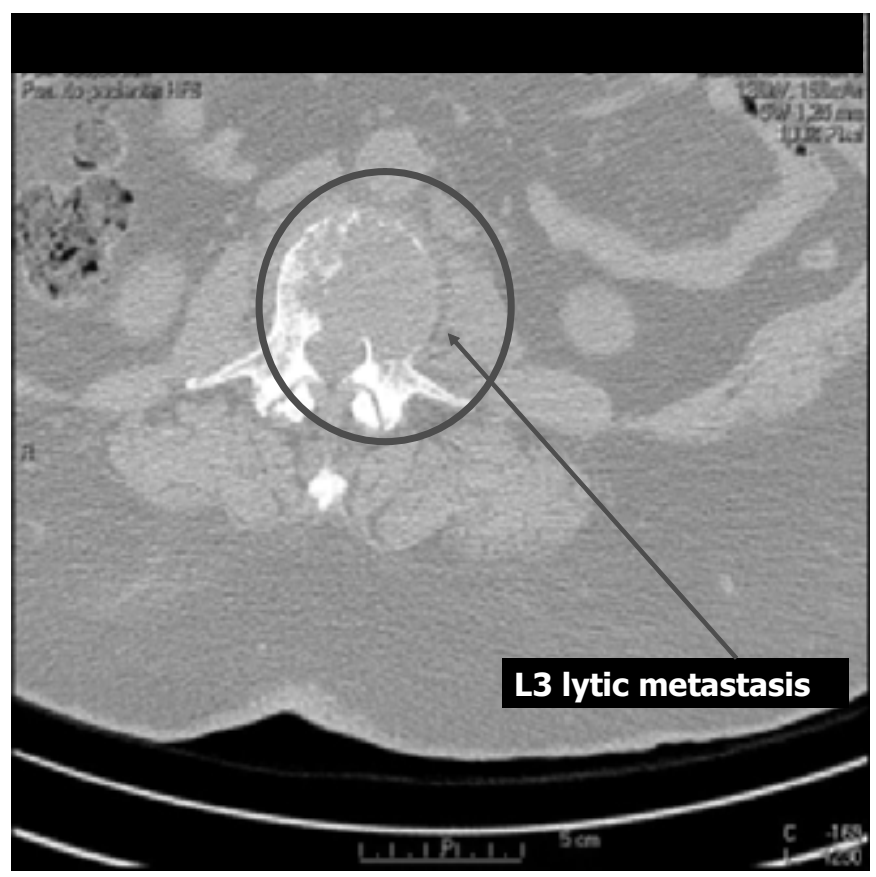

Fig. 3. Computed tomography scan of lumbar spine.

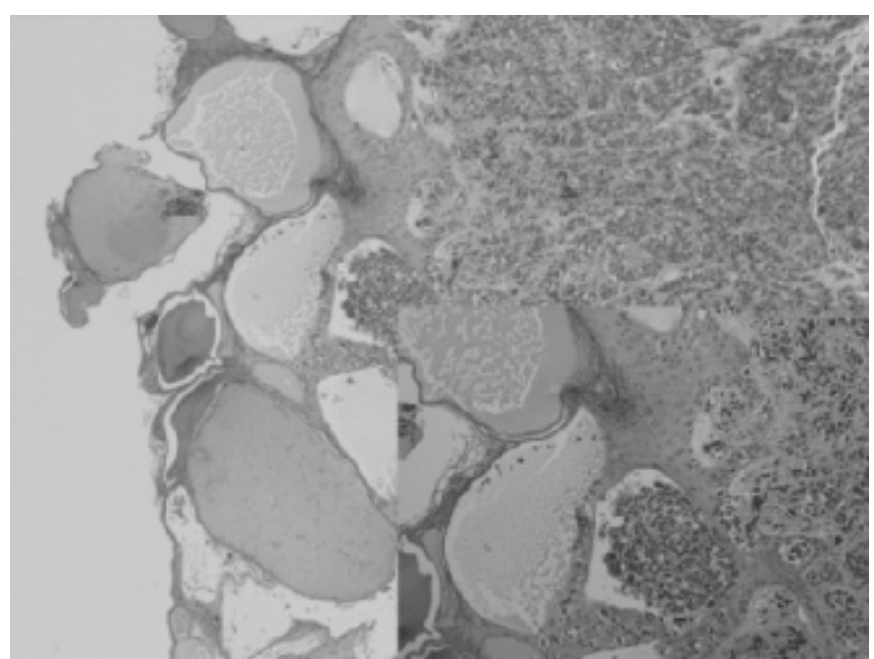

Fig. 4. Dermal invasion without lymphatic involvement.

\section{Discussion}

Inflammatory breast cancer is an aggressive and poorly understood disease with symptoms that differ from other types of breast cancer. At the time of diagnosis, most women have lymph node metastases, and roughly one third will have distant metastases. It accounts for an estimated $2 \%$ of breast cancer diagnoses in the U.S., but for $7 \%$ of breast cancer deaths [1].

The classic and clinical description was provided by Tannenbaum and Lee in 1924 when they cited: 'The rate of growth 
is startling in its rapidity and often fills the entire breast in a few weeks... the overlying skin is reddened and brawny and its blush may extend far beyond the limits of the mammary gland... the inflamed area presents a distinct raised periphery after the fashion of erysipelas. The infiltration is so marked that the examiner, with his eyes closed, can distinguish readily the sharp contrast between normal and affected tissue' [6]. In 1938, Taylor and Meltzer divided the inflammatory breast cancer in 2 distinct categories, primary and secondary, based on whether we deal with an ad hoc nosologic entity in the first case or with a locally advanced cancer that presents inflammatory signs in the second one [7].

According to the pathologic findings, the major determinant of this tumour entity is the dermal lymphatic invasion by carcinoma, but this invasion does not consist in a sine qua non condition. The diagnosis of this nosologic entity still relies on clinical features, and several centres have proposed various end points, like for example the one cited by the M.D. Anderson Cancer Center: '...our diagnostic criteria for primary breast cancer include clinical evolution shorter than 3 months'.

This specific case is a typical controversial case because there is still disagreement over whether it can be classified as primary or secondary inflammatory breast cancer $[2,3]$. Besides the clinical features present (oedema, peau d'orange, and erythema developed over a short period of 2 months) and the absence of a concrete palpable mass, no dermal lymphatic invasion was detected in the histological examination and there is a history of a long-standing uncharacterized breast lump and areolar-nipple invasion. Whether we are dealing with a primary inflammatory breast carcinoma with secondary local invasion, or with secondary inflammatory breast cancer due to local invasion of a primary lump, the finding of oestrogen receptor positivity was quite surprising [4]. Independent of its classification, in this specific case, we are dealing with TNM stage IV metastatic disease.

\section{Conclusion}

Inflammatory breast carcinoma still remains a challenging issue with regard to diagnosis and treatment. Its differentiation into primary and secondary disease needs to be more clarified since the two forms entail distinct management and prognosis. Recent inflammatory breast carcinoma research has examined two genes, RhoC GTPase and WISP3, which are concordantly altered in the majority of inflammatory breast tumours but not in non-inflammatory specimens [5]. A better definition of the clinical features of inflammatory breast cancer needs to be achieved. Currently ongoing clinical trials aim at a better understanding and differentiation of this rare but extremely aggressive type of breast cancer.

\section{Acknowledgement}

We thank Paula Vasconcelos and Ana Rios for their contribution to the immediate radiological staging of the patient.

\section{Conflict of Interest}

The authors declare that they have no competing interests.

\section{References}

1 Merajver SD, Sabel MS: Inflammatory breast cancer; in Harris JR, Lippman ME, Morrow M, Osborne CK (eds): Diseases of the Breast, 3rd ed. Philadelphia, PA, Lippincott Williams and Wilkins, 2004, pp. 971-982.

2 Lerebours F, Bieche I, Lidereau R: Update on inflammatory breast cancer. Breast Cancer Res 2005; 7:52-58.
$\$ 3$ Giordano SH, Hortobagyi GN: Inflammatory breast cancer: clinical progress and the main problems that must be addressed; review. Breast Cancer Res 2003;5:284-288.

4 Silva O, Zurrida S: Breast Cancer. A Practical Guide, 3rd ed. Edinburgh, Elsevier Saunders, 2005, p. 236.
5 Houchens NW, Merajver SD: Molecular determinants of the inflammatory breast cancer phenotype. Oncology (Williston Park) 2008;22:1556-1561.

6 Lee BJ, Tannenbaum NE: Inflammatory carcinoma of the breast: a report of twenty-eight cases from the breast clinic of Memorial Hospital. Surg Gynecol Obstet 1924;39:580-595.

7 Taylor GW, Meltzer A: Inflammatory carcinoma of the breast. Am J Cancer 1938;33:33-49. 